\title{
Anger in young martial arts and combat sports practitioners: effects of six-month regular training
}

\author{
Jorge Carlos LAFUENTE*1, Roberto RUIZ-BARQUÍN2 ${ }^{*}$, Carlos GUTIÉRREZ-GARCÍA ${ }^{1}$, \& Marta \\ ZUBIAUR $^{1}$ \\ ${ }^{1}$ Universidad de León (Spain) \\ 2 Universidad Autónoma de Madrid (Spain)
}

\section{5th IMACSSS World Scientific Congress Abstracts, Rio Maior (Portugal), October 6-8 Section: Psychological, pedagogic and didactics in MA\&CS Type: Poster communication}

\section{Introduction}

Martial arts and combat sports (MA\&CS) practice has been usually recommended for children and youngsters in order to get positive developments in the physical, psychological and socio-affective dimensions (Tadesse, 2015). Specifically, MA\&CS have been associated with the control of negative emotions - such as fear or anger -, although there is no conclusive evidence on the positive socialpsychological effects of their practice (Vertonghen \& Theeboom, 2010). This study, which was aimed at describing and comparing anger in a sample of young MA\&CS regular practitioners with an interval of six months, seeks to add more evidence to this controversial topic.

\section{Methodology}

Eighty-two youngsters ( 27 females and 52 males), aged between 9 and 12 years old ( $M=10.21 ; S D$ $=1.06$ ) participated in this quasi-experimental, pre-post (two groups, one quasi control group), longitudinal study (Montero \& León, 2007). A natural control group $(n=45)$ formed by 15 females and 30 males $\left(M_{\text {age }}=10.18\right.$; $\left.S D_{\text {age }}=.86\right)$ was compared to an experimental group $(n=37)$ formed by 12 females and 25 males $\left(M_{\text {age }}=10.18 ; S D_{\text {age }}=1.28\right)$. Youngsters in the control group were Primary Education students from a local public school, while the experimental group was formed by MA\&CS practitioners regularly involved in judo $(n=19)$ or karate $(n=18)$ training - around one hour, twice or three times a week - in one of six clubs, and their experience in practicing these martial arts ranged from 2 months to 8 years $(M=43.03$ months, $S D=25.31)$. We also compared judo (5 females and 14 males) to karate practitioners ( 7 females and 11 males). Anger was measured using a Spanish version of the State-Trait Anger Expression Inventory for Children and Adolescents (STAXINA) (Spielberger, Del Barrio, \& Aluja, 2005). Particularly, we used the Trait Anger (Temperament and Reaction) and the Anger Expression and Control (Anger-in expression, Anger-out expression, Anger-in control and Anger-out control) subscales. This study did not imply any specific intervention based on anger management but the regular disciplinary or educational procedures used by instructors in their classes. After getting informed consent from their parents, practitioners filled out the questionnaire during the first twenty minutes of two regular training or physical education sessions - at the beginning of December and at the end of May. Descriptive statistics as well as non-parametric procedures (Mann-Whitney $U$ test for inter-group comparison and Wilcoxon signed-rank test for intra-group comparison) were used for data analysis.

\section{Results}

The pre-test showed differences in anger-in expression $\left(U_{M-W}=617 ; p=.042\right)$, with the control group $(M=7.29, S D=1.95)$ achieving higher scores than the experimental group $(M=6.41, S D=$ 
2.01), but the post-test did not reveal any significant difference between groups. In the same way, there were no differences between the pre-test and post-test neither in the experimental group nor in the control group. With regard to judo and karate practitioners groups, there were no differences between groups neither in the pre-test nor in the post-test. Judo group had no differences between the pre-test and post-test, while differences were found in anger-out expression in karate group $\left(Z_{W}\right.$ $=-2,247 ; p=.025)$, with higher scores in the post-test $(M=7.44, S D=2.48)$ than in the pre-test $(M=$ $6.61, S D=2.10$ ).

\section{Discussion and conclusion}

This study showed that six-month MA\&CS training produced no effect on anger management. There were only one positive difference between the experimental and the control group, and one negative difference within the karate group in the pre and post-tests. Results of similar quasiexperimental, pre-post longitudinal studies conducted on aggression in youngsters (Reynes \& Lorant, 2002a,b, 2004) are only partially in tune with our study, as they found higher anger in the judo group than in the karate group and in the control group after one and two years of practice, while there were no differences between the karate and the control groups. This suggests that, generally speaking, MA\&CS training per se has no effect on anger management in youngsters. Despite our study having some limitations (mainly small sample size), it is important to note the difficulties in carrying out these studies and the importance of accumulating evidence on the psychological effects of MA\&CS training.

\section{References}

Montero, I., \& León, O. G. (2007). A guide for naming research studies in Psychology. International Journal of Clinical and Health Psychology, 7(3), 847-862.

Reynes, E., \& Lorant, J. (2002a). Effect of traditional judo training on aggressiveness among young boys. Perceptual and Motor Skills, 94(1), 21-25.

Reynes, E., \& Lorant, J. (2002b). Karate and aggressiveness among eight-year-old boys. Perceptual and Motor Skills, 94(3), 1041-1042.

Reynes, E., \& Lorant, J. (2004). Competitive martial arts and aggressiveness: A 2-yr. longitudinal study among young boys. Perceptual and Motor Skills, 98(1), 103-115.

Spielberger, C. D., Del Barrio, M. V., \& Aluja, A. (2005). STAXI-NA. Inventario de expresión de ira estado-rasgo en niños y adolescentes. Madrid: TEA Ediciones.

Tadesse, M. (2015). The role of taekwondo training on the subjective wellbeing of adolescents in Addis Ababa, Ethiopia. Revista de Artes Marciales Asiáticas, 10(2), 72-87.

Vertonghen, J., \& Theeboom M. (2010). The social-psychological outcomes of martial arts practise among youth: A review. Journal of Sports Science and Medicine, 9(4), 528-537.

Key words: Anger; STAXI-NA; Martial arts; Combat sports; Judo; Karate. 